\title{
Recent Developments and Aspects of Industrial Fluoroalkylation
}

\author{
Matthias Bellera ${ }^{a}$, Florian Fischera ${ }^{a}$ Andreas Locher ${ }^{b}$, Helfried Neumann ${ }^{a}$, Christoph Taeschlerb, \\ Fei Ye ${ }^{\mathrm{a}}$, and Shaoke Zhang ${ }^{\mathrm{a}}$
}

\begin{abstract}
Fluoroalkylations have received increasing attention in the academic and industrial environment due to the particular properties of the active ingredients that are strongly influenced by fluoroalkyl substituents. The inherent difficulties of introducing a fluoroalkyl substituent into advanced intermediates has triggered the development of an enormous number of specialized reagents, which, however, are often not suitable for large scale applications. In contrast to this reagent based fluoroalkylation approach, the direct activation of industrially readily available fluoroalkyl halides could be more suitable for a large-scale process. In this way the dithionite initiated fluoroalkylation as well as newly developed catalytically activated fluoroalkylation protocols were considered for industrial large-scale applications.
\end{abstract}

Keywords: Catalysis · Dithionite · Fluoroalkylation · Industry $\cdot$ Sulfinatodehalogenation

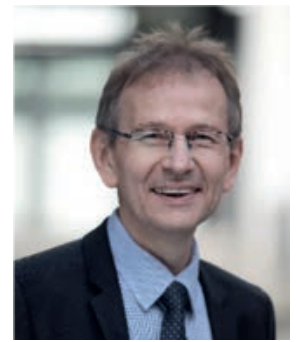

Matthias Beller, born in Gudensberg (Germany) in 1962, obtained his $\mathrm{PhD}$ in 1989 working with Lutz F. Tietze at the University of Göttingen. After one year of post-doctoral research with Barry Sharpless at MIT (USA), from 1991 to 1995 he worked at Hoechst AG in Frankfurt. Then, he started his academic career at TU Munich. In 1998, he relocated to Rostock to head the Leibniz Institute for Catalysis. Matthias Beller is also Vice-president of the Leibniz Association and a member of 3 German Academies of Sciences including the German National Academia 'Leopoldina'. The research of his group has been published in more than 1040 original articles and reviews and focused on applying homogeneous and heterogeneous catalysis for the synthesis of fine/bulk chemicals as well as energy technologies. He is married to Anja Fischer-Beller and they have two sons.

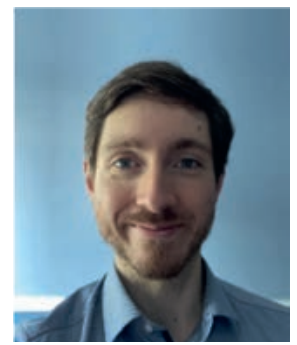

Florian Fischer graduated in organic chemistry in the Group of Prof. Langer in 2015 in Rostock, Germany and pursued his research at the Leibniz Institute of Catalysis in the group of Prof. Beller in cooperation with Lonza AG under supervision of Dr. Taeschler to provide new ecological, economical and chemical ways for the fluoroalkylation of small molecules. He currently works in the biopharma industry.
${ }^{*}$ Correspondence: Dr. C. Taeschlerb, E-mail: christoph.taeschler@arxada.com, aLeibniz-Institut für Katalyse an der Universität Rostock e.V.,

Albert-Einstein-Strasse 29a, 18059 Rostock (Germany);

${ }^{b}$ Arxada AG, Lonzastrasse, CH-3930 Visp, Switzerland;

Authors in alphabetical order

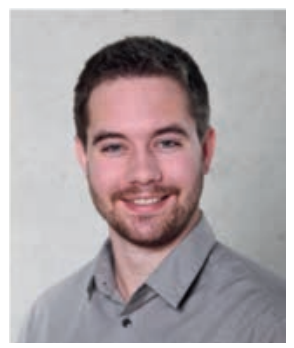

Andreas Locher started his career as a chemical lab technician at Lonza in Switzerland, before graduating in molecular life sciences specializing in chemistry in 2016 at the University of Applied Sciences and Arts Northwestern Switzerland (FHNW). Andreas is currently undertaking his master studies at FHNW in cooperation with the Linköping University in Sweden.

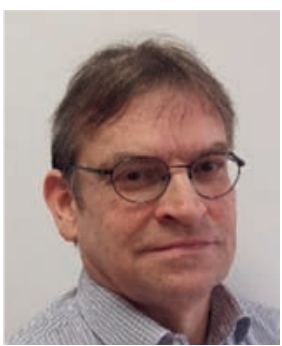

Helfried Neumann finished his PhD studies in 1995 at the University Erlangen under the supervision of Prof. Rainer Herges and Prof. Paul Rague von Schleyer. In 1996, he joined the Institute of Organic Catalysis in Rostock (IfOK, which was later renamed to Leibniz-Institute für Katalyse e.V.) and became project leader since 1998. His current research activities are concerned with carbonylation reactions, 'hydrogen-borrowing' concept, perfluoroalkylation of arenes and the development of new ligands.

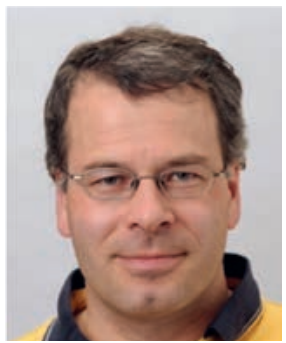

Christoph Taeschler gained his $\mathrm{PhD}$ in 1999 in organic chemistry under der supervision of Prof. Ted S. Sorensen at the University of Calgary. Then he joined Lonza AG in Visp, Switzerland in the Research and Development department for life science intermediates. In 2006, he joined Operations at Lonza as a production team leader until 2009, when he moved back to Research and Development as a project leader and technical group leader for chemists. In 2021, he moved to the newly founded Arxada AG, where his current activities involve the development and optimization of large-scale processes. 


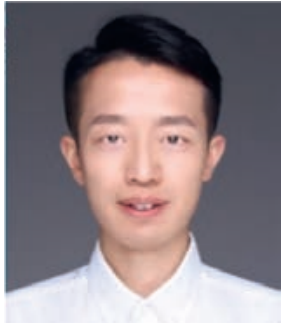

Fei Ye was born in Hunan, he obtained his $\mathrm{PhD}$ from the University of Paris VI (France) in 2017 under the supervision of Dr. V. Ratovelomanana-Vidal and Prof. Véronique Michelet. He worked with Prof. Matthias Beller at the Leibniz Institute for Catalysis (LIKAT), Rostock in Germany, as a postdoctoral fellow from 2018 to 2020 . Fei's research transitioned to the synthesis of fluoro-substituted functional molecules. Now, he is an associate professor at Hangzhou Normal University. His current research focuses on ligand synthesis, organosilicon chemistry, and asymmetric catalysis.

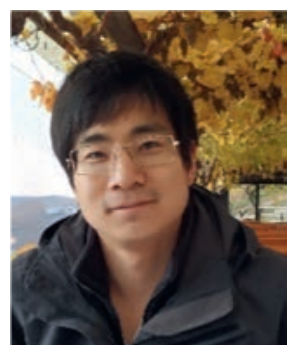

Shaoke Zhang obtained his bachelor and master degree in applied chemistry in 2012 and 2015 in China. In 2016, he joined the group of Prof. Matthias Beller at the Leibniz Institute for Catalysis, and received his $\mathrm{PhD}$ in 2019. During this period, he investigated the direct perfluoroalkylation of arenes and alkenes using perfluoroalkyl iodides. Related results of fluoroalkylation chemistry were published in four scientific articles.

\section{Introduction}

Numerous active ingredients in the pharmaceutical and agrochemical industries as well as material sciences ${ }^{[1]}$ contain fluorine $^{2}$ as a crucial part, determining the desired properties of the ingredient to a large extent. In this way, $16 \%$ of the top 200 drugs, ${ }^{[2]} 45 \%$ of the $2018^{[3]}$ and $41 \%$ of the $2019{ }^{[4]}$ FDA approved drugs are fluorine containing. Similarly, nearly $60 \%$ of the active ingredients for the agrochemical industry contain fluorine. Most of these products contain fluorine in form of a fluoroalkyl group. Thus, the introduction of such fluoroalkyl groups has been subject to an enormous amount of academic activity with an ever-increasing number of publications appearing in all major chemistry journals (Science Finder, Fig. 1).

A clear overall understanding from these investigations shows the high complexity of introducing such fluoroalkyl groups with a strongly dependence on the substrate and the fluoroalkyl reagent. Therefore, numerous academic synthetic protocols have been developed involving the use of specialized reagents[5] (reagentbased approach). However, many of these specialized reagents have more than 5 times the weight of the fluoroalkyl group being transferred. The preparation of these reagents themselves pose many challenging steps and recycling of the reagent is rarely fea-

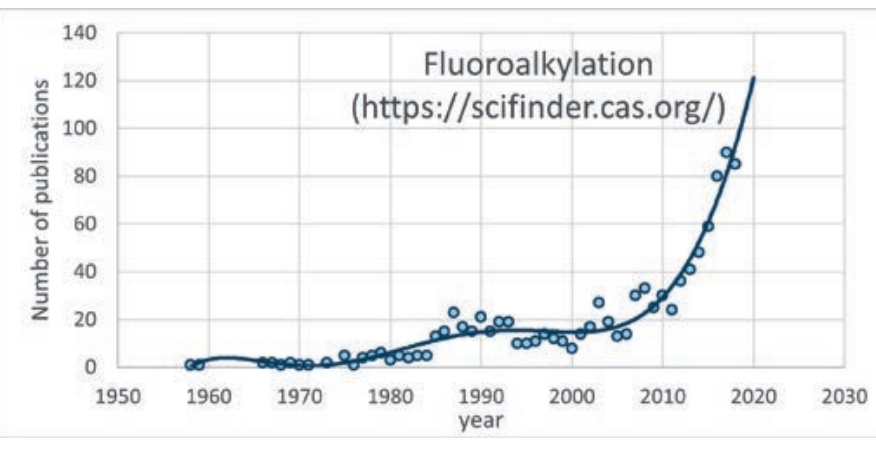

Fig. 1. Number of publications published in every year according to Science Finder (https://scifinder.cas.org/) over the last few decades.

sible. Therefore, the use of these reagents is generally not suitable for industrial large-scale applications due to the significant amounts of waste generated (low atom efficiency) and due to the prohibitively high costs. Hence, the reagent-based approach of fluoroalkylation remains reserved for very specialized applications in academic or medicinal environments ${ }^{[6]}$ as illustrated in Scheme 1.

The currently available industrial products containing fluoroalkyl groups are almost exclusively produced by a so-called 'downstream' approach. This approach makes use of fluorinated starting materials with the desired fluorine substituents in place at a very early stage. Since many products in question require a lengthy synthesis, the loss of the fluorinated part in the molecule often becomes the main cost driver.

Focusing on large-scale production of fluoroalkylated products, we identified the need for industrially viable fluoroalkylation methods that allow the introduction of fluoroalkylation substituents at a late stage, making use of industrially available starting materials and avoiding the use of expensive and waste intensive reagents.

The development of a fluoroalkylation reaction for an industrial large-scale process requires the consideration of numerous aspects such as toxicity-, waste- and environmental-, corrosion-, and energetic- (thermodynamics and kinetics) issues and of course the cost arising from the selection of starting materials. With these requirements in mind, we focused on two general methods for the industrial fluoroalkylation:

1. Dithionite initiated fluoroalkylation (also referred to as sulfinatodehalogenation)

2. Catalytic initiated fluoroalkylation

Since the consideration of all industrially relevant aspects would be far beyond the scope of this publication, focus is devoted to reactivity and energetic aspects.
Scheme 1. Selected examples of reagent-based fluoroalkylation reactions.

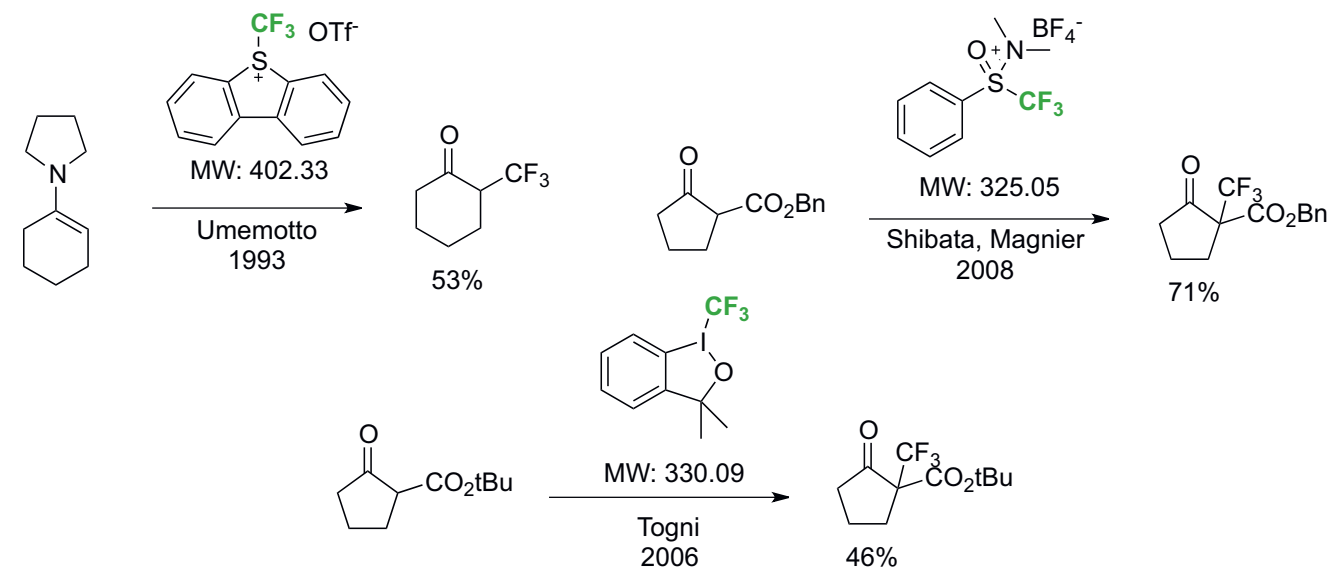




\section{Results and Discussion}

\subsection{Reactivity Considerations}

The selection of industrially adequate starting materials is a crucial part at the beginning of every process development. Regarding fluoroalkylation reactions, an obvious starting material selection concerns fluoroalkyl halides. Despite the environmentally hazardous ozone-depleting properties, these compounds are used as early fluorinated intermediates in a number of large volume (>100'000 to/a) applications. ${ }^{[7]}$ The ready availability for attractive costs provides valuable possibilities when a strict emission control can be assured.

Considering several fluoroalkyl halides as starting material for fluoroalkylation reactions, specific knowledge of their reactivities and some mechanistic understanding of the respective reaction in question is of great importance for process development. In most cases, it is notoriously difficult to gain detailed knowledge on the reaction mechanism with good evidence. It is not surprising that little is known on most reaction mechanisms when industrial processes are being developed. Nevertheless, it is useful to have a proposal of a reaction mechanism, which helps to direct the development efforts where it is most needed.

The two industrially promising fluoroalkylation reactions in focus involve most likely fluoroalkyl radicals as reactive intermediates. ${ }^{[8]}$ The activation of the fluoroalkyl starting material to form corresponding fluoroalkyl radicals is a crucial step, which determines the course of the fluoroalkyl reaction to a large extent. The bond dissociation energies of fluoroalkyl halides can be used to estimate the ease of the fluoroalkyl radical formation as listed in Table 1.

Several experimental dissociation energies are available for a few perfluoroalkyl halides. ${ }^{[9]}$ The combination of experimental values and some DFT calculations were used to select the cheapest yet adequately accurate level of theory. Interestingly, the much faster and straightforward BP86 DFT functional performs better than the hybrid functionals B3LYP and wB97XD and even the

Table 1. Dissociation energies of selected fluoroalkyl halides. Selected experimental values were taken from ref. [9]. Calculated values were obtained through DFT calculations using the BP86//def3TZVP, B3LYPD3//def2TZVP, wB97XD//def2TZVP and B2PLYD3//def2TZVPP level of theory. All values given are in $\mathrm{kJ} / \mathrm{mol}$.

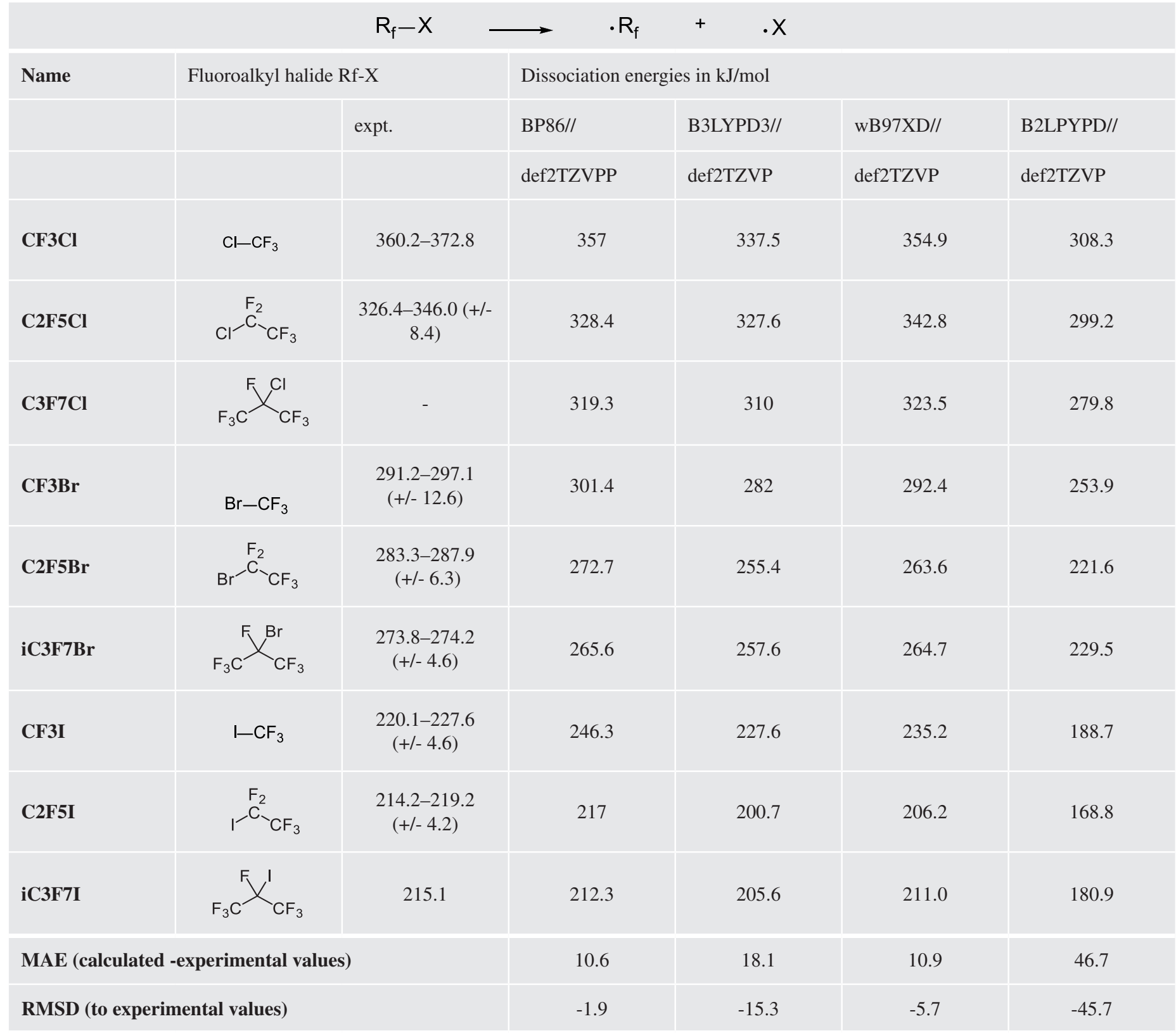


significantly more expensive B2PLYP double hybrid functional. We believe the reason for this behavior is the higher sensitivity of the wavefunction components in B3LYP, wB97XD and even more so in the B2PLYP functional toward spin contamination and the multireference character treating radical species. ${ }^{[10]}$

A comparison of the electrostatic charge distribution of methyl bromide and trifluoromethyl bromide (see Fig. 2) illustrates the distinct difference in the charge density at the bromide. The reduction of the negative charge explains the need for an electron-rich radical initiator for an efficient activation of perfluoroalkyl halides.

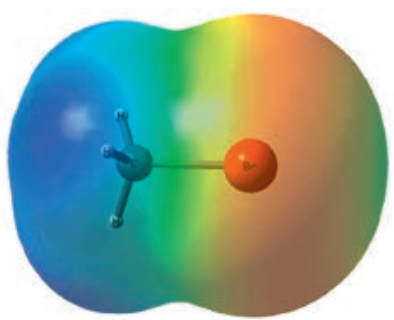

Methyl bromide

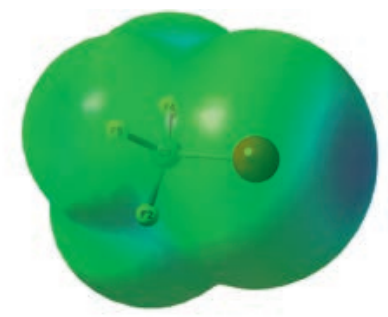

Trifluoromethyl bromide
Fig. 2. Electrostatic potential surface of methyl bromide and trifluoromethyl bromide calculated at BP86/TZVP using the SMD solvation model with acetonitrile parameters. Blue color is positively charged, red color is negatively charged.

With an increasing fluoroalkyl substitution on the halide bond carbon, a decrease of the negative charge on the halide as well as an increasing lower LUMO energy level is observed (see Table 2 ). This behavior agrees well with the experimentally observed increased reactivity of fluoroalkyl halides with higher fluoroalkyl substitution pattern. ${ }^{[8 a, c . e]}$

\subsection{The Dithionite Method}

A well-suited initiator reagent for fluoroalkyl halides is sodium dithionite, first discovered by Huang and co-workers in 1981.[11]

Table 2. Mulliken charges of the halide (where not otherwise stated) and the energy level of the frontier orbitals calculated at the BP86 /TZVP level of theory using the SMD solvation model with acetonitrile parameters.

\begin{tabular}{|l|l|l|l|}
\hline & $\begin{array}{l}\text { Mulliken } \\
\text { Charges } \\
\text { at the halide }\end{array}$ & $\begin{array}{l}\text { HOMO } \\
\text { energy level } \\
\text { in } \mathbf{e V}\end{array}$ & $\begin{array}{l}\text { LUMO } \\
\text { energy level } \\
\text { in } \mathbf{~ V V}\end{array}$ \\
\hline $\mathbf{C H 3 B r}$ & -0.128 & -0.24806 & -0.042526 \\
\hline $\mathbf{C F 3 B r}$ & -0.050 & -0.29007 & -0.08606 \\
\hline $\mathbf{C 2 F 5 B r}$ & -0.044 & -0.28988 & -0.09168 \\
\hline $\mathbf{C 3 F 7 B r}$ & -0.029 & -0.29278 & -0.09952 \\
\hline C4F9Br & 0.003 & -0.29494 & -0.11197 \\
\hline CF3CI & -0.054 & -0.31587 & -0.05557 \\
\hline CF3I & -0.024 & -0.26273 & -0.11207 \\
\hline
\end{tabular}

Sodium dithionite is known to be in equilibrium with the sulfur dioxide radical anion (Scheme 2). ${ }^{[12]}$

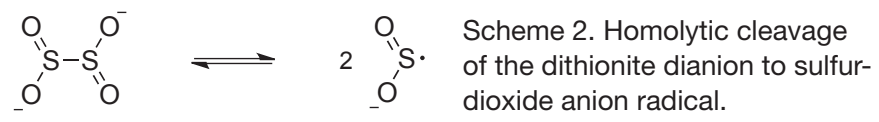

The high electron density of the sulfur dioxide anion radical and the rather electrophilic character of the halides in the fluoroalkyl halides explain the high reactivity of the dithionite system to activate many perfluoroalkyl iodides and bromides (Fig. 3). Perfluoroalkyl chlorides are significantly less reactive. Polar solvents such as DMSO and DMF at elevated temperature are necessary for their activation. ${ }^{[13]}$

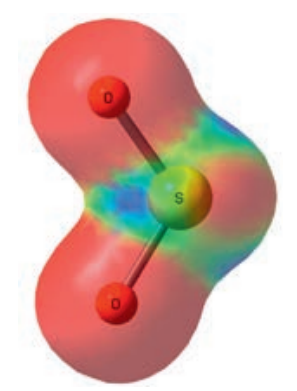

Fig. 3. Electrostatic potential surface of the sulfur dioxide anion radical calculated at $\mathrm{BP} 86 / \mathrm{TZVP}$ using the SMD solvation model with acetonitrile parameters.

According to multiple mechanistic investigations of the dithionite method, the involvement of perfluoroalkyl radicals is widely accepted. ${ }^{[8, \mathrm{a}, \mathrm{c}, \mathrm{e}]}$ Using DFT calculations on the trifluoromethyl bromide, the formation of an intermediate adduct (SO2-CF3-Br-ar) is suggested, which separates into the bromosulfite anion ( $\mathrm{SO} 2 \mathrm{Br}-\mathrm{a})$ and the trifluoromethyl radical (CF3-r) (Fig. 4). A SET process from the intermediate adduct (SO2-CF3Br-ar) with subsequent fragmentation into sulfur dioxide and trifluoromethyl bromide anion radical $(\mathrm{CF} 3 \mathrm{Br}$-ar) or bromide and the trifluoromethyl radical (CF3-r) was found to be energetically less favorable.

The perfluoroalkyl radical reacts with several substrates to form fluoroalkylated products. ${ }^{[8 a, c-e, 14]}$ Despite several investigations on the dithionite method, a conclusive reaction mechanism has not been published to the best of our knowledge. Within our work we considered the following proposed reaction pathways (Scheme 3).

The reaction of the fluoroalkyl radical with aniline is proposed to react to an intermediate radical (CF3Ar), which could further react in four different ways to the desired fluoroalkylated product. One possibility would be the recombination with a fluoroalkyl halide $(\mathrm{CF} 3 \mathrm{Br})$ to enter a radical chain mechanism. Usually, the yields of the reaction drop significantly if sub-stoichiometric amounts of sodium dithionite are used, indicating that the propagation cycle is not efficient. The intermediate radical (CF3Ar) could also be converted to the product in three different termination reactions:

- Reaction with the solvent to transfer a hydride

- Combination with the sulphur dioxide radical anion

- Recombination with an addition fluoroalkyl radical to form the reduced fluoroalkane.

The reduction of the fluoroalkyl halide to the fluoroalkane is a well-known side reaction of the radical fluoroalkylation. Several investigations have been conducted to find the source of the hydrogen for the reduction of the fluoroalkane. ${ }^{[8 \mathrm{~d}, 14 \mathrm{a}]}$ Réglier and co-workers have conducted deuterium-labelled studies on the addition of the difluoroacetyl radical to phenylacetylene or bromostyrene. ${ }^{[15]}$ Within their studies the solvent DMSO, the starting 

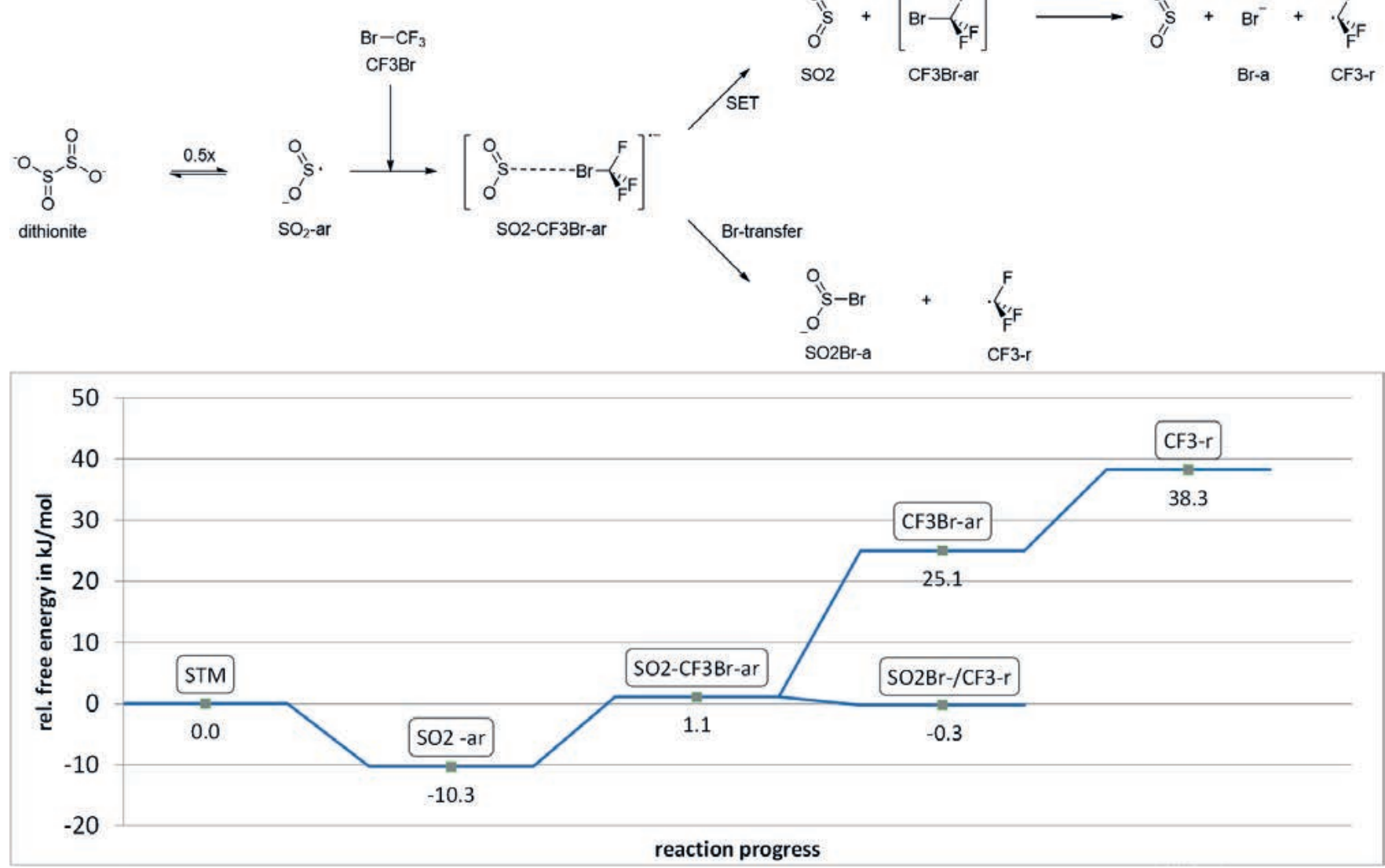

Fig. 4. Relative free energies of the activation process of trifluoromethyl bromide by dithionite. The calculated energies were obtained by DFT calculations at a BP86/TZVP level of theory using the SMD solvation model with acetonitrile parameters.
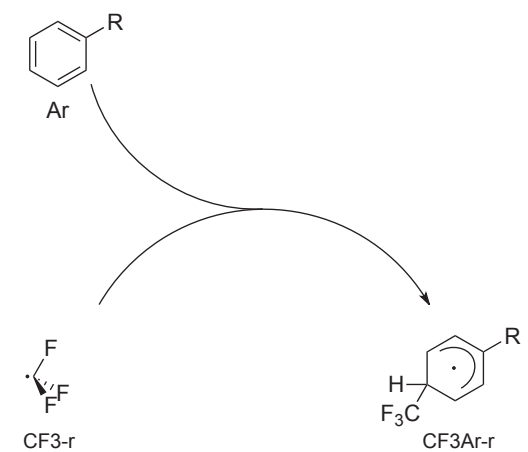

CF3-r

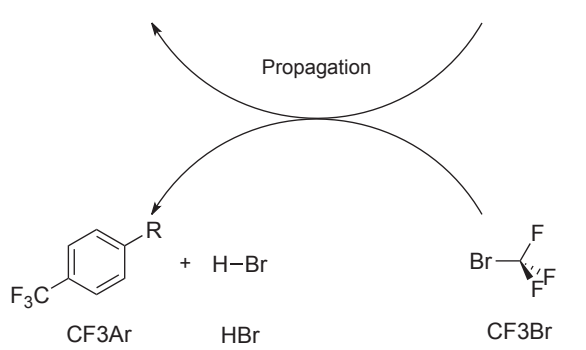

material phenylacetylene or the water used in the workup could be ruled out as the source of the hydrogen for the reduction of the fluoroalkyl reagent. Their conclusion was that the hydrogen is supplied by the base $\mathrm{NaHCO}_{3}$ used in this reaction. Within our work, many examples have been studied in acetonitrile, without the addition of $\mathrm{NaHCO}_{3}$ as a base. Even though the commercially available
Scheme 3. Possible mechanistic pathways considered within the dithionite development work. sodium dithionite contains about $15 \%$ of $\mathrm{Na}_{2} \mathrm{CO}_{3}$, no corresponding hydrogen could be supplied directly from any $\mathrm{NaHCO}_{3}$.

The reduction of the fluoroalkyl halide to the fluoroalkane is inherently associated with a loss on yield. The extent of this side reaction depends mostly on the nature of the substrate, but also on the perfluoroalkyl reagent and the conditions. In general, the use of 
more electron-rich aromatic substrates results in higher yields and less formation of the reduced fluoroalkane as illustrated in Table 3.

This effect could be explained by a faster reaction rate of the electrophilic fluoroalkyl radical with an electron-rich substrate compared to an electron-deficient substrate. In this way, the steady state concentration of the fluoroalkyl radical would be reduced and the competitive reaction pathway to form the reduced fluoroalkane through a corresponding termination reaction would be smaller. The reduction of fluoroalkyl halides to fluoroalkanes in the absence of a substrate has been investigated by Howell, Wakselman and Zhang, ${ }^{[8,14 a, 16]}$ indicating that a radical mechanism should be involved.

The high yield of electron-rich substrates and the straightforward method of the dithionite initiator system for fluoroalkylations makes this protocol a valuable possibility. ${ }^{[8 d]}$ In at least a few cases, this possibility was used to develop an industrial process such as shown in Scheme 4. ${ }^{[17]}$

\subsection{Catalytic Fluoroalkylation Methods}

Limitations of the dithionite method arise for less electronrich substrates such as pyridines, acetophenones or fluoroalkylated substrates. In these reactions, the reduction of the fluoroalkyl halide becomes dominant at the cost of the product yield (Table 3). This provided motivation to search for improved fluoroalkylation methods. In this respect, we found that promising approaches could be the catalytically initiated fluoroalkylation methods. In the search for appropriate catalysts, we developed two protocols utilizing noble metal catalysts that showed good activities for a number of substrates with different fluoroalkyl iodides and bromides ${ }^{[8 f, g, 18]}$ as illustrated in Table 4.
Table 3. Fluoroalkylation of selected substrates using the dithionite initiation protocol. Conditions: Ethyl acetate/ $\mathrm{H}_{2} \mathrm{O}$ as solvent, $20^{\circ} \mathrm{C}, 5 \mathrm{~h}$, tetrabutyl ammonium bromide as phase transfer catalyst.<
Scheme 4. Fluoroalkylation in industrial processes for the production of Nicofluprole and Broflanilide. ${ }^{[17]}$

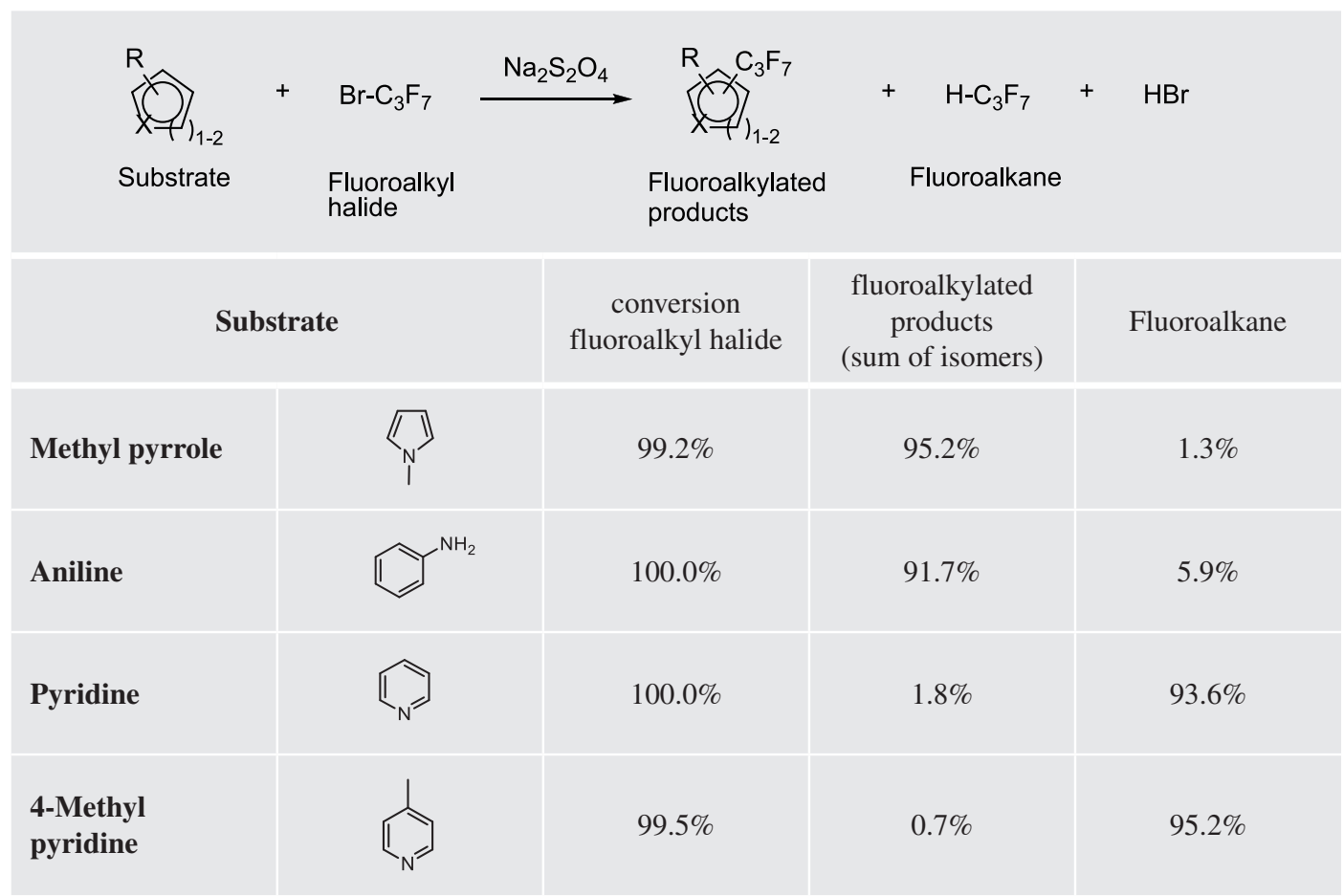

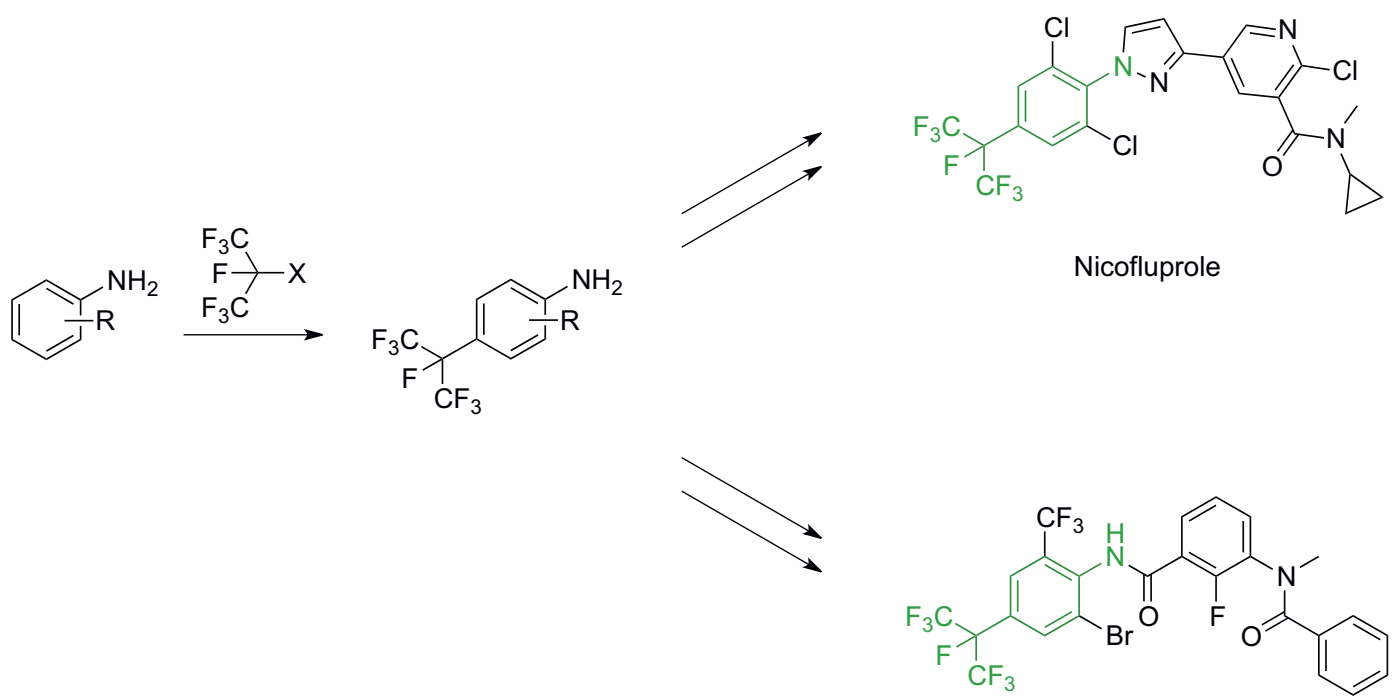

Broflanilide 


\begin{tabular}{|c|c|c|c|}
\hline Substrate & fluoroalkyl halide & Protocol & yield \\
\hline & $\mathrm{I}-\mathrm{C}_{8} \mathrm{~F}_{17}$ & $\mathrm{Pt} / \mathrm{C}$ & $79 \%{ }^{a}$ \\
\hline & $\mathrm{Br}-\mathrm{C}_{8} \mathrm{~F}_{17}$ & $\mathrm{Pt} / \mathrm{C}$ & $54 \%^{\mathrm{b}}$ \\
\hline & $\mathrm{Br}-\mathrm{CF}_{3}$ & $\mathrm{Pt} / \mathrm{C}$ & $21 \%^{\mathrm{c}}$ \\
\hline & $\mathrm{I}-\mathrm{C}_{10} \mathrm{~F}_{21}$ & $\mathrm{Pt} / \mathrm{C}$ & $\begin{array}{c}94 \% \\
(2 \text {-isomer })^{d}\end{array}$ \\
\hline & $\mathrm{I}-\mathrm{C}_{10} \mathrm{~F}_{21}$ & $\mathrm{Pt} / \mathrm{C}$ & $\begin{array}{c}65 \% \\
(2,3,4 \text {-isomers })^{c}\end{array}$ \\
\hline & $\mathrm{I}-\mathrm{C}_{10} \mathrm{~F}_{21}$ & $\mathrm{Pt} / \mathrm{C}$ & $69 \%^{c}$ \\
\hline & $\mathrm{Br}-\mathrm{CF}_{3}$ & Pd-BuPAd ${ }_{2}$ & $72 \% \mathrm{e}^{\mathrm{e}}$ \\
\hline & $\mathrm{Br}-\mathrm{CF}_{3}$ & Pd-BuPAd ${ }_{2}$ & $80 \% \mathrm{e}^{\mathrm{e}}$ \\
\hline & $\mathrm{Br}-\mathrm{CF}_{3}$ & Pd-BuPAd ${ }_{2}$ & $\begin{array}{c}47 \% \\
(3 \text {-isomer) }\end{array}$ \\
\hline
\end{tabular}

Table 4. Selected examples of the noble metal-catalysed fluoroalkylation using $\mathrm{Pt} / \mathrm{C}^{[8]}$ or $\mathrm{Pd}-\mathrm{BuPAd}_{2}$ catalysts. ${ }^{[8]}$ Conditions: a) $\mathrm{Pt} / \mathrm{C}$ (Pt 5 mol\%), 1 eq. $\mathrm{Cs}_{2} \mathrm{CO}_{3}$, neat, $\left.100{ }^{\circ} \mathrm{C}, 15 \mathrm{~h}, \mathrm{~b}\right) \mathrm{Pt} / \mathrm{C}$ (Pt $5 \mathrm{~mol} \%$ ), 1 eq. $\mathrm{Cs}_{2} \mathrm{CO}_{3}$, neat, $100{ }^{\circ} \mathrm{C}$, 40 h, c) Pt/C (Pt 5 mol\%), 1 eq. $\mathrm{Cs}_{2} \mathrm{CO}_{3}$, neat, $\left.100{ }^{\circ} \mathrm{C}, 20 \mathrm{~h} \mathrm{~d}\right)$ $\mathrm{Pt} / \mathrm{C}$ (Pt 5 mol\%), 1 eq. $\mathrm{Cs}_{2} \mathrm{CO}_{3}$, neat, $50{ }^{\circ} \mathrm{C}, 20 \mathrm{~h}$, e) $10 \mathrm{~mol} \%$ $\mathrm{Pd}(\mathrm{OAc})_{2}, 20 \mathrm{~mol}^{2} \mathrm{BuPAd}_{2}$, acetone, 2 eq. $\mathrm{Cs}_{2} \mathrm{CO}_{3}, 1$ eq. TEMPO, $130^{\circ} \mathrm{C}, 40 \mathrm{~h}$.
The $\mathrm{Pt} / \mathrm{C}$ protocol makes use of the commercially available platinum on charcoal (e.g. $5 \mathrm{wt} \% \mathrm{Pt} / \mathrm{C}$ from Sigma Aldrich 330159). The homogeneous catalyst in the Pd-BuPAd ${ }_{2}$ protocol was prepared in situ by adding palladium acetate and the phosphine ligand di(1-adamantyl)-n-butylphosphine $\left(\right.$ BuPAd $\left._{2}\right)$ in a stoichiometric ratio of 1:2 to the reaction mixture (Fig. 5). The formation of the $\operatorname{Pd}\left(\operatorname{BuPAd}_{2}\right)_{2}$ catalyst is proposed to form in situ by an initial ligation of the palladium acetate by two $\mathrm{BuPAd}_{2}$ ligands, which then reduce palladium (II) to palladium (0) in accordance with the investigations of Amatore and Jutand. ${ }^{[19]}$

In analogy to the dithionite initiation method, electron-rich substrates react in higher yields to the desired fluoroalkylated products for both protocols. However, electron-neutral or even electron-deficient substrates such as pyridine or pyrazine could be converted to the fluoroalkyl products in reasonable yields. Notably, longer chain fluoroalkyl halides react faster as well as iodides, which are more reactive than the corresponding bromides.

EPR measurements during the reaction with both noble metalbased protocols showed distinct signals of the fluoroalkyl radicals indicating the involvement of fluoroalkyl radicals ${ }^{[8, \mathrm{~g}, 22]}$ as also suggested for the dithionite initiation. ${ }^{[8 \mathrm{a}-\mathrm{c}, \mathrm{e}]}$ Interestingly, the two catalytic protocols showed a distinctly different reactivity with the addition of the radical scavenger TEMPO ((2,2,6,6-tetramethylpiperidin-1-yl)oxyl). While the reactivity of the $\mathrm{Pt} / \mathrm{C}$-protocol is completely suppressed, the Pd-BuPAd ${ }_{2}$-protocol experienced a significant activation with the addition of TEMPO. To learn more about the nature of this behavior, mechanistic investigations were conducted on the homogeneous Pd-BuPAd, protocol. ${ }^{[8 \mathrm{~g}]}$ Using DMPO (5,5-dimethyl-pyrroline $\mathrm{N}$-oxide) as spin trapping reagent, the short-living $\mathrm{CF}_{3}$ radical could be detected using EPR measurements confirming a radical mechanism of the reaction as proposed in Scheme 5. The electrophilic $\mathrm{CF}_{3}$ radical is believed to react directly with the aromatic substrate to form the conjugated radical $(\mathbf{C})$. After the abstraction of a hydrogen by $(\mathbf{B})$, the catalytic intermediate (D) and fluoroalkylated product is formed. The accelerating effect of TEMPO for this reaction is explained by supporting the regeneration of the catalytic intermediate $(\mathbf{B})$ from (C). Supporting EPR results for this proposal could be acquired by subsequently adding $\mathrm{HBr}$ and $\mathrm{Cs}_{2} \mathrm{CO}_{3}$ to TEMPO and detecting a reduction and increase of the EPR signal. The intermediate (D) could be detected by NMR measurements providing additional support of the proposed mechanism in Scheme 5.

In general, the two noble metal-catalyzed fluoroalkylation protocols provide a valuable possibility to overcome problems with the dithionite method predominantly with electron-deficient substrates. The high costs of the catalysts, however, as well as the rather sluggish reaction progress in the case of the heterogeneous platinum catalyst for fluoroalkyl bromides and the industrially rather limited availability of the homogeneous palladium-BuPAd catalyst motivated us to develop more practical protocols. In this 
Fig. 5. In situ formation of the Pd-BuPAd ${ }_{2}$ catalyst with a geometry optimized structure of the proposed pre-catalyst $\mathrm{Pd}\left(\mathrm{BuPAd}_{2}\right)_{2}(\mathrm{OAc})_{2}$ at the BP86// defTZVP level of theory using the COSMO-RS solvation model ${ }^{[20]}$ as well as a crystal structure of the proposed catalyst $\mathrm{Pd}\left(\mathrm{BuPAd}_{2}\right)_{2}{ }^{\left[{ }^{[21]}\right.}$

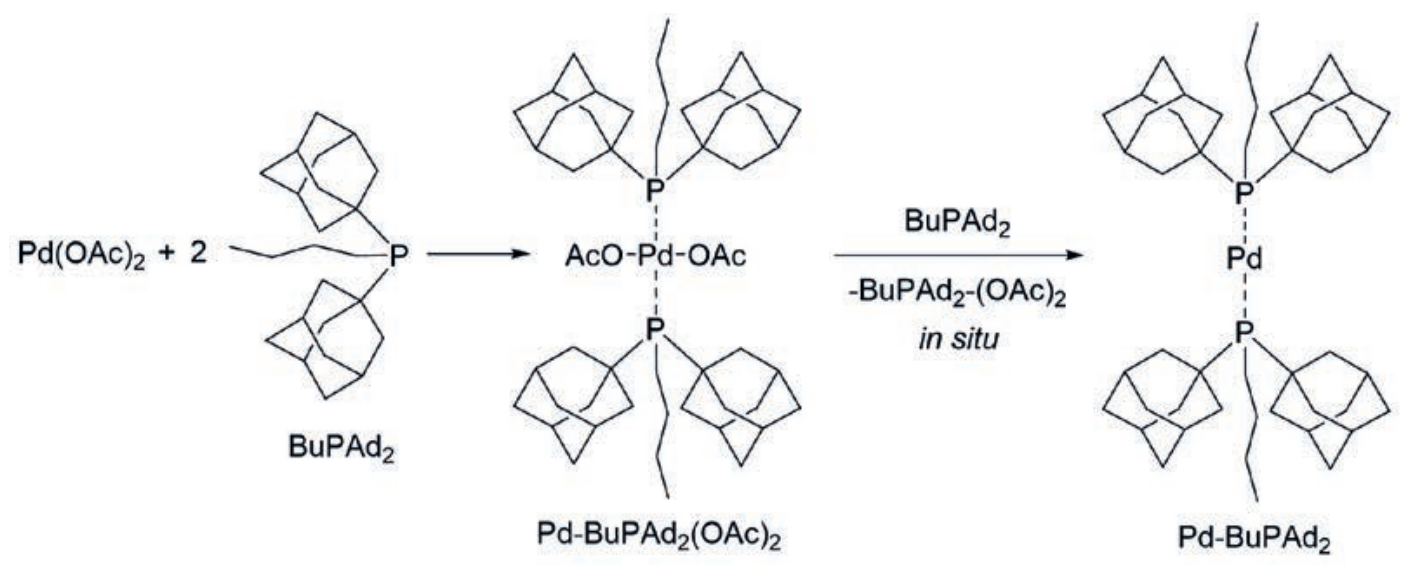

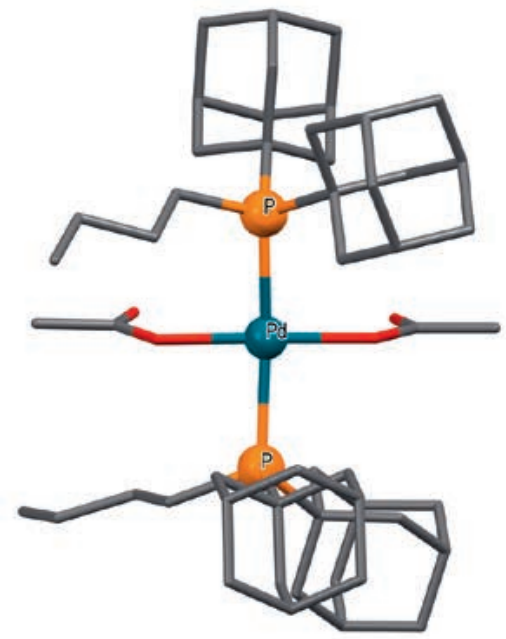

$\operatorname{Pd}\left(\operatorname{BuPAd}_{2}\right)_{2}(\mathrm{OAc})_{2}$

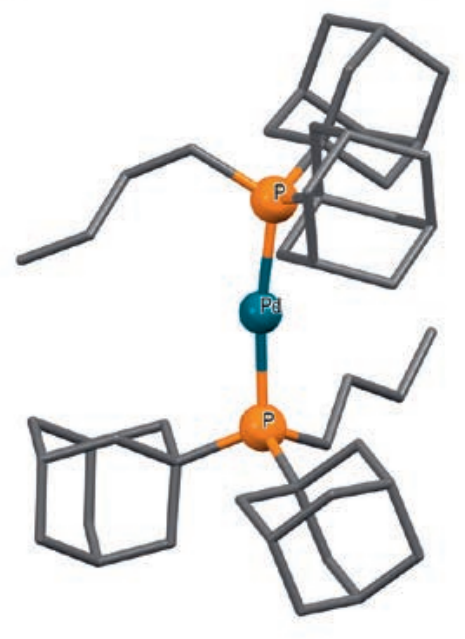

$\operatorname{Pd}\left(\operatorname{BuPAd}_{2}\right)_{2}$ way, first row transition metal catalysts were investigated for their applicability in fluoroalkylation reactions using readily and industrially available fluoroalkylating reagents. These include fluoroalkyl bromides rather than iodides due to cost and waste considerations.

Following this approach two additional catalytic fluoroalkylation protocols could be discovered employing a heterogeneous cobalt (Co@N/C) $)^{[23]}$ or a homogeneous nickel catalyst (Ni-dppf) system (Table 5).[8h,i,23,24]

The usability of cobalt nanoparticles on N-doped carbon $((\mathrm{Co} @ \mathrm{~N} / \mathrm{C}))$ for fluoroalkylation reactions was discovered within a broad screening involving more than 100 catalysts.[23] The preparation of the catalyst was conducted by the complexation of cobalt salts with 1,10-phenanthroline, absorbing the complex on activated charcoal (Vulcan XC72R from Cabot) and pyrolysis at 600 to $1000{ }^{\circ} \mathrm{C}^{[25]}$ illustrated in Scheme 6 .

The remarkable reactivity of the heterogeneous Co@N/C system towards rather electron-deficient systems showed the great potential of this protocol (Table 5), which motivated us to investigate and optimize the reaction with an industrial focus. In this way, the following parameters were screened with 4-picoline and acetophenone as substrates:

- Catalyst modifications (metal type, metal loading, metal precursor, catalyst support, pyrolysis condition)

- Reaction temperature

- Bases

- Solvents

- Additives

- Catalyst recycling

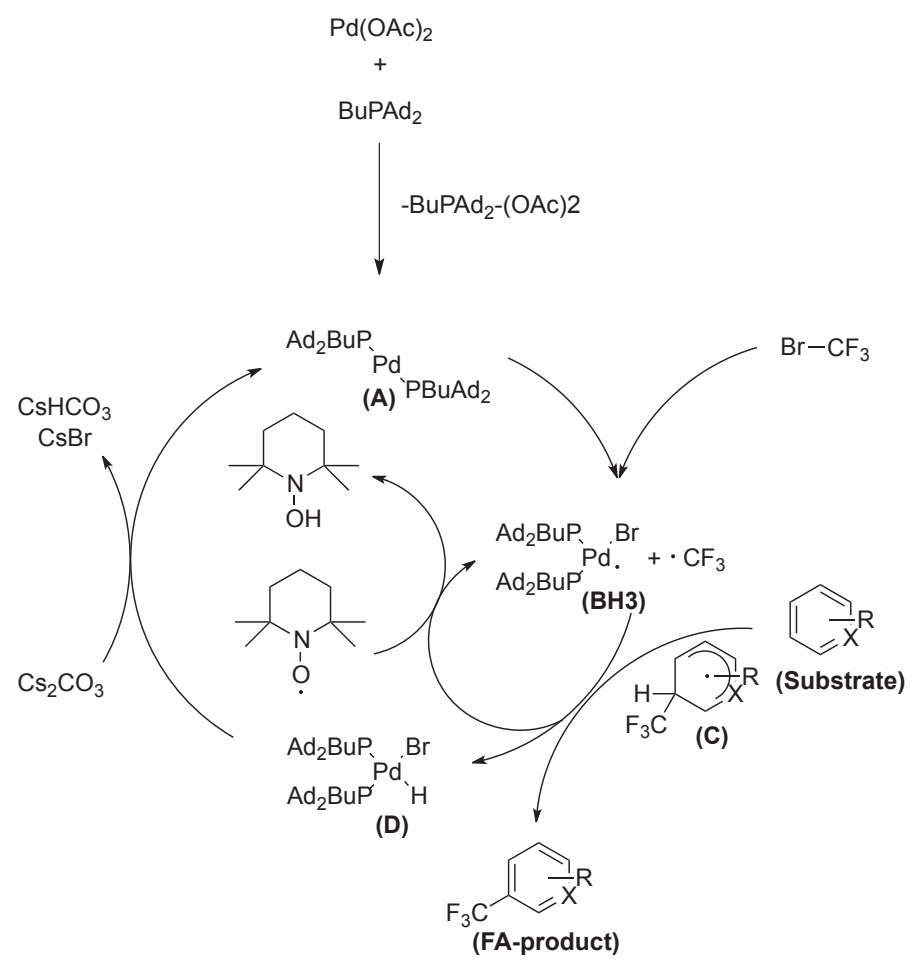

Scheme 5. Proposed mechanism for the homogeneous catalyzed fluoroalkylation using Pd-BuPAd ${ }_{2}$ catalyst 

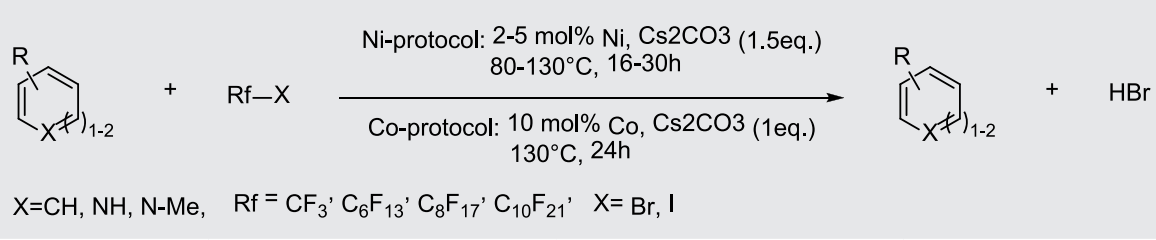

$\mathrm{X}=\mathrm{CH}, \mathrm{NH}, \mathrm{N}-\mathrm{Me}, \quad \mathrm{Rf}=\mathrm{CF}_{3}{ }^{\prime} \mathrm{C}_{6} \mathrm{~F}_{13}{ }^{\prime} \mathrm{C}_{8} \mathrm{~F}_{17} \mathrm{C}_{10} \mathrm{~F}_{21}, \quad \mathrm{X}=\mathrm{Br}$,

\begin{tabular}{|c|c|c|c|}
\hline Substrate & Fluoroalkyl halide & protocol & yield \\
\hline & $\mathrm{I}-\mathrm{C}_{10} \mathrm{~F}_{21}$ & Ni-dppf/100 ${ }^{\circ} \mathrm{C} / 16 \mathrm{~h}$ & $75 \%$ \\
\hline & $\mathrm{I}-\mathrm{C}_{10} \mathrm{~F}_{21}$ & Ni-dppf/130 ${ }^{\circ} \mathrm{C} / 16 \mathrm{~h}$ & $\begin{array}{c}91 \% \\
(2,3,4 \text {-isomers) }\end{array}$ \\
\hline & $\mathrm{I}-\mathrm{C}_{10} \mathrm{~F}_{21}$ & Ni-dppf/120 ${ }^{\circ} \mathrm{C} / 16 \mathrm{~h}$ & $\begin{array}{c}55 \% \\
(2,3,4 \text {-isomers })\end{array}$ \\
\hline & $\mathrm{I}-\mathrm{C}_{10} \mathrm{~F}_{21}$ & Ni-dppf/100 ${ }^{\circ} \mathrm{C} / 30 \mathrm{~h}$ & $\begin{array}{c}96 \% \\
(3,4-\text { isomers })\end{array}$ \\
\hline & $\mathrm{I}-\mathrm{C}_{10} \mathrm{~F}_{21}$ & $\mathrm{Ni}$-dppf $/ 80^{\circ} \mathrm{C} / 16 \mathrm{~h}$ & $\begin{array}{c}86 \% \\
\text { (2-isomer) }\end{array}$ \\
\hline & $\mathrm{Br}-\mathrm{CF}_{3}$ & Ni-dppf/100 ${ }^{\circ} \mathrm{C} / 16 \mathrm{~h}$ & $\begin{array}{c}72 \% \\
\text { (2-isomer) }\end{array}$ \\
\hline & $\mathrm{I}-\mathrm{C}_{10} \mathrm{~F}_{21}$ & Ni-dppf/130 ${ }^{\circ} \mathrm{C} / 26 \mathrm{~h}$ & $\begin{array}{c}60 \% \\
(2,3,4 \text {-isomer })\end{array}$ \\
\hline & $\mathrm{I}-\mathrm{C}_{10} \mathrm{~F}_{21}$ & Ni-dppf/130 ${ }^{\circ} \mathrm{C} / 16 \mathrm{~h}$ & $\begin{array}{c}96 \% \\
\text { (3-isomer) }\end{array}$ \\
\hline & $\mathrm{Br}-\mathrm{C}_{6} \mathrm{~F}_{13}$ & $\mathrm{Co} @ \mathrm{~N} / \mathrm{C} / 130^{\circ} \mathrm{C} / 24 \mathrm{~h}$ & $>99 \%$ \\
\hline & $\mathrm{Br}-\mathrm{C}_{6} \mathrm{~F}_{13}$ & $\mathrm{Co} @ \mathrm{~N} / \mathrm{C} / 130^{\circ} \mathrm{C} / 24 \mathrm{~h}$ & $\begin{array}{c}92 \% \\
(2,3,4 \text {-isomers })\end{array}$ \\
\hline & $\mathrm{Br}-\mathrm{C}_{6} \mathrm{~F}_{13}$ & $\mathrm{Co} @ \mathrm{~N} / \mathrm{C} / 130{ }^{\circ} \mathrm{C} / 24 \mathrm{~h}$ & $\begin{array}{c}98 \% \\
\text { (2-isomer) }\end{array}$ \\
\hline & $\mathrm{Br}-\mathrm{C}_{6} \mathrm{~F}_{13}$ & $\mathrm{Co} @ \mathrm{~N} / \mathrm{C} / 130^{\circ} \mathrm{C} / 24 \mathrm{~h}$ & $\begin{array}{c}80 \% \\
(3,4,5 \text {-isomers })\end{array}$ \\
\hline & $\mathrm{Br}-\mathrm{C}_{6} \mathrm{~F}_{13}$ & $\mathrm{Co} @ \mathrm{~N} / \mathrm{C} / 130^{\circ} \mathrm{C} / 24 \mathrm{~h}$ & $\begin{array}{c}84 \% \\
(2,3,4 \text {-isomers) }\end{array}$ \\
\hline & $\mathrm{Br}-\mathrm{C}_{6} \mathrm{~F}_{13}$ & $\mathrm{Co} @ \mathrm{~N} / \mathrm{C} / 130^{\circ} \mathrm{C} / 24 \mathrm{~h}$ & $\begin{array}{c}84 \% \\
(2,3,4 \text {-isomers })\end{array}$ \\
\hline & $\mathrm{Br}-\mathrm{CF}_{3}$ & $\mathrm{Co} @ \mathrm{~N} / \mathrm{C} / 130^{\circ} \mathrm{C} / 48 \mathrm{~h}$ & $\begin{array}{c}41 \% \\
(2,3,4 \text {-isomers })\end{array}$ \\
\hline
\end{tabular}


Scheme 6. Preparation of the Co@N/C catalyst according to ref. [25].
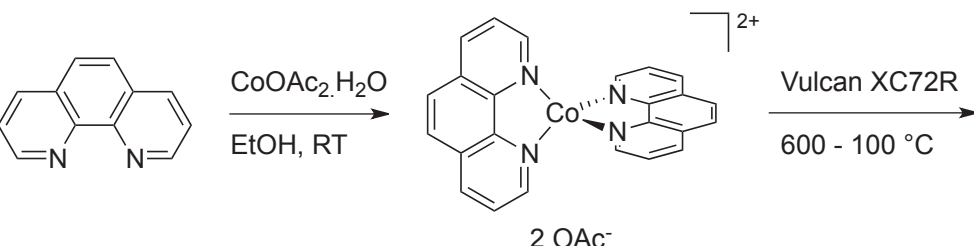

$2 \mathrm{OAc}^{-}$

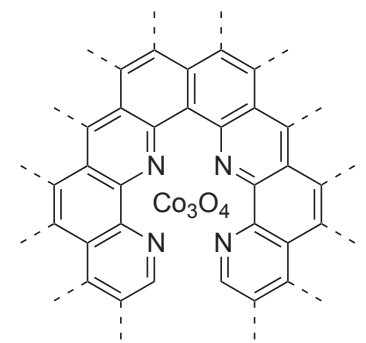

Fig. 6. Parameter variations with the reaction of 4-picoline with perfluorohexyl bromide using the Co@C/N protocol. Optimized conditions: Co@N/C from $\mathrm{Co}(\mathrm{OAc})_{2} \cdot 4 \mathrm{H}_{2} \mathrm{O}$, pyrolysis at $800{ }^{\circ} \mathrm{C}, 1$ eq. $\mathrm{Cs}_{2} \mathrm{CO}_{3}$, neat, $130^{\circ} \mathrm{C}, 24 \mathrm{~h}$.

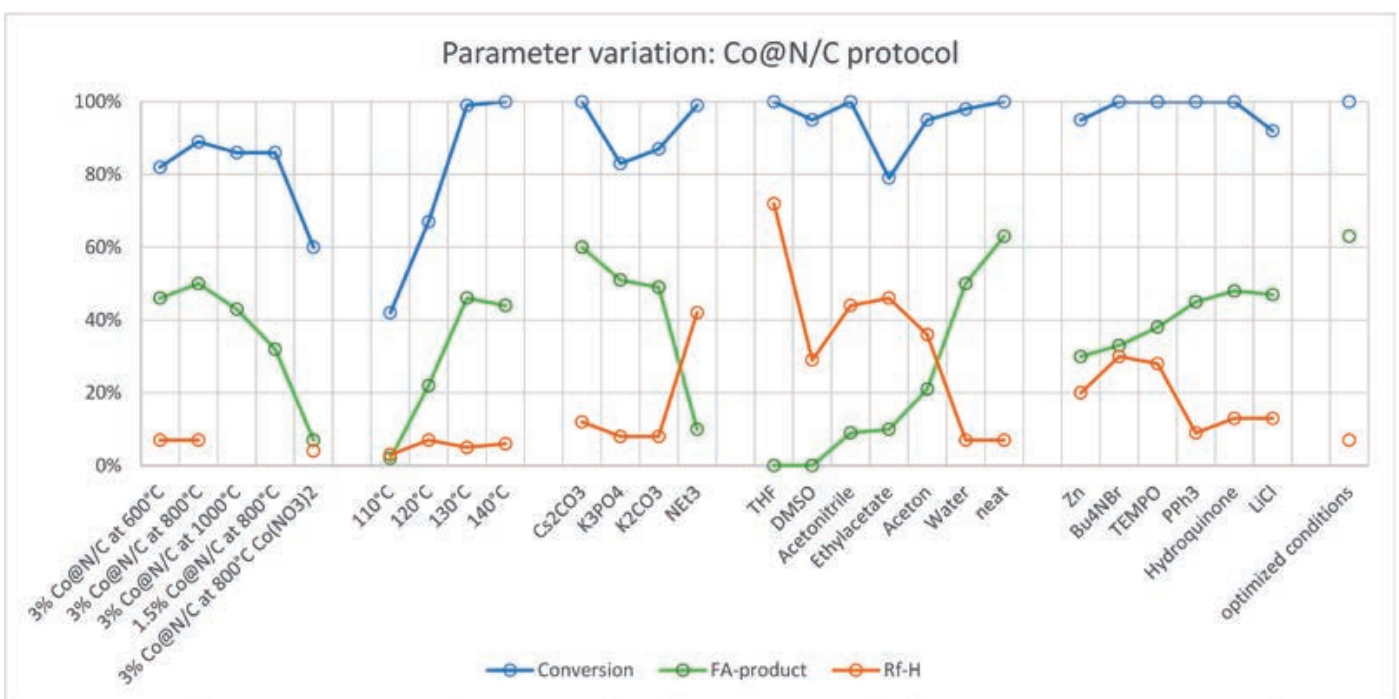

Using 4-picoline as substrate, the fluoroalkylation reaction was tested by altering one parameter at a time. The results are illustrated in Fig. 6 showing groups at the horizontal axes with the variations of each parameter.

In contrast to prior applications ${ }^{[25,26]}$ of the Co@N/C showing high sensitivity to the pyrolysis conditions, the use in fluoroalkylation reactions was strongly influenced by the anion of the starting metal salt. The use of $\mathrm{Co}(\mathrm{OAc})_{2} \cdot 4 \mathrm{H}_{2} \mathrm{O}$ yielded the most active catalyst. Reaction temperatures of $130{ }^{\circ} \mathrm{C}$ were found to be optimal for the 4-picoline reaction giving complete conversion and the highest yield. While the use of $\mathrm{Cs}_{2} \mathrm{CO}_{3}$ gave the best results, its industrial use is significantly more expensive compared to corresponding potassium bases. The result of this base screening is of special industrial interest as only a small reduction of the yield needs to be expected when switching from $\mathrm{Cs}_{2} \mathrm{CO}_{3}$ to $\mathrm{K}_{2} \mathrm{CO}_{3}$ or $\mathrm{K}_{3} \mathrm{PO}_{4}$. Surprisingly, the addition of any solvent to this system decreased the product yield and increased the reduction of fluoroalkyl halide significantly. This indicates that the solvent could supply the hydrogen for the reduction of the fluoroalkyl halide in this reaction regime as earlier discussed for the dithionite-initiated protocol. Further support of the solvent acting as hydrogen donor for the reduction of the fluoroalkyl halide was observed in control experiments with fluoroalkylating benzene, toluene and mesitylene, where the amount of the reduced fluoroalkyl halide was measured at $0 \%, 9 \%$ and $45 \%$, respectively. ${ }^{[23]}$

The addition of additives was investigated by different means. For example, the addition of radical scavengers often reveals some important details on the reaction mechanism. In this protocol, the addition of TEMPO or hydroquinone did not stop the reaction. Only a slight increase of the reduced fluoroalkyl halide and a slight decrease of the yield was measured. This is in strong contrast to the Ni-based protocol, in which the addition of TEMPO completely stopped the reaction. ${ }^{[8 \mathrm{~h}, \mathrm{i}]} \mathrm{EPR}$ measurements and the addition of the spin-trapping reagent DMPO did not yield any information of a short-living radical being involved.[23]
Having found reaction conditions of the Co@N/C protocol for electron-deficient aromatic systems, we were interested in the possibility of recycling the catalyst. We tested the fluoroalkylation for the difficult examples of 4-picoline with perfluorohexyl bromide and acetophenone with trifluoromethyl bromide by multiple use of the same catalyst as shown in Fig. 7.

The catalyst recycling experiments of acetophenone with trifluoromethyl bromide showed no reactivity change over six reaction cycles. Some bistrifluoromethylation was detected with $3-7 \%$. In the case of the 4-picoline, the activity of the catalyst remained at the initial level for four cycles. Only the $5^{\text {th }}$ and $6^{\text {th }} \mathrm{cy}-$ cles showed a deactivation of the catalyst. Analysis of the catalyst after each cycle showed continuous decrease of the cobalt content from $3.1 \%$ to $0.5 \%$. The fluorine content increased already after the first usage cycle to approximately $15 \%$, indicating a fluoroalkylation of the surface of the catalyst. This change did not have

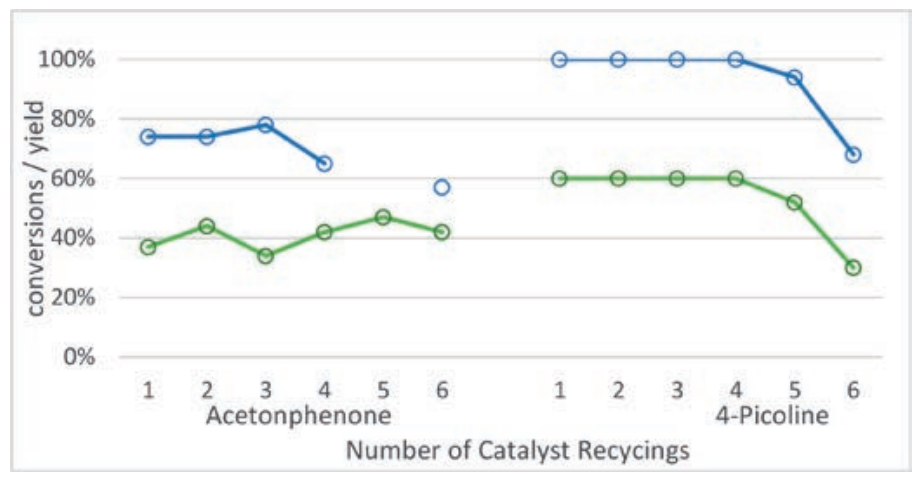

Fig. 7. Catalyst recycling for the Co@N/C catalyzed fluoroalkylation. Conditions: Acetophenone, $10 \mathrm{ml} \% \mathrm{Co} @ \mathrm{~N} / \mathrm{C}, \mathrm{CF}_{3}-\mathrm{Br}, 1.5$ eq. $\mathrm{Cs}_{2} \mathrm{CO}_{3}$, acetone, $130{ }^{\circ} \mathrm{C}, 48$ h. 4-Picoline: $10 \mathrm{ml} \% \mathrm{Co} @ \mathrm{~N} / \mathrm{C}$, perfluorohexyl bromide, 1 eq $\mathrm{Cs}_{2} \mathrm{CO}_{3}$, neat, $130^{\circ} \mathrm{C}, 24 \mathrm{~h}$. 
an influence on the reactivity of the catalyst as it remained active for another three cycles.

Even though a cobalt leaching was recognized for the fluoroalkylation of 4-picoline, the re-use of the catalyst for four to five cycles is impressive. The possibility of reusing the catalyst for a catalytic fluoroalkylation protocol for four and more times provides a realistic industrial potential.

The nickel-catalyst (Ni-dppf) showed some interesting activities towards electron-rich substrates as well as rather electron-deficient substrates. The sensitivity towards the type of the fluoroalkyl halide and the nature of the substrate seems to affect the course of the reaction to a smaller extent compared to the dithionite initiation (see Table 3 ). The preparation of the catalyst requires some effort, however provides an air-stable system ${ }^{[27]}$ as shown in Scheme 7.

The required conditions for this catalytic system are crucial to obtain good yields. For example, the use of $\mathrm{Cs}_{2} \mathrm{CO}_{3}$ as a base is required to obtain any conversion and the use of several solvents increased the reduction of the fluoroalkyl halide to the fluoroalkane to a large extent. The compliance to these reaction conditions bears significant drawbacks to an industrial application, which motivated us to search for solutions to extend the condition tolerance of this protocol. A hint for further improvement provided the experiments with added ammonium or sodium formate, which shortened the reaction time to full conversion from $10 \mathrm{~h}$ to $2 \mathrm{~h}$ with an increase in yield.

Further optimization efforts were directed towards simplifying the phosphine ligand replacing the $\mathrm{Cs}_{2} \mathrm{CO}_{3}$ base and finding the best reaction conditions. To our delight, the in situ generation of the catalyst by adding $\mathrm{Ni}\left(\mathrm{NO}_{3}\right)_{2} \cdot 2 \mathrm{H}_{2} \mathrm{O}$ and 2 equivalents of triphenylphosphine $\left(\mathrm{PPh}_{3}\right)$ to the reaction mixture proved to be remarkably active with the addition of a reducing agent. This catalytic system was further optimized by varying following parameters:
- Reducing agent: Zn-powder, formic acid, Na-formate, hydroquinone

- Base: $\mathrm{Cs}_{2} \mathrm{CO}_{3}, \mathrm{~K}_{2} \mathrm{CO}_{3}, \mathrm{~K}_{3} \mathrm{PO}_{4}$, triethylamine,

- Solvent: butyl acetate, butyl acetate $/ \mathrm{H}_{2} \mathrm{O}$, acetonitrile, neat

- Temperature: $50-90{ }^{\circ} \mathrm{C}$

- Reaction time: 4-24 h

In Fig. 8, the variation of these parameters is shown in groups, in which only one parameter at a time was changed.

Industrially most interesting are the conditions with $\mathrm{K}_{2} \mathrm{CO}_{3}$ as a base and hydroquinone or $\mathrm{Na}$-formate reducing agent as additive. Indicated by the results of the various screening experiments and from a rational understanding of the fluoroalkylation reaction, the reaction temperature and time are most likely dependent on each other, hence their optimization was conducted within experimental design as shown in Fig. 9.

Within these experiments, the best temperature-time range of $70-80{ }^{\circ} \mathrm{C}$ as well as $15-20 \mathrm{~h}$ could be identified, providing a yield of more than $95 \%$ with less than $0.6 \%$ of the reduced fluoroalkane as side product. These results provide a very attractive outlook for this protocol regarding industrially applicable fluoroalkylations outperforming the extensively optimized dithionite method. In this way, the nickel-catalyzed protocol appears to be particularly interesting for the preparation of fluoroalkylated anilines, which are valuable precursors for active ingredients such as broflanilide ${ }^{[28]}$ or nicoflupyrole. ${ }^{[17 e-g]}$

\section{Conclusions}

The immense amount of work over several decades in the realm of fluoroalkylations reflect the inherent difficulty of this type of reaction. The huge selection of sophisticated reagents for the introduction of fluoroalkylation substituents at a late stage are most useful for medicinal or specialized small-scale and high-priced applications. Industrially viable protocols for larger scale applica-

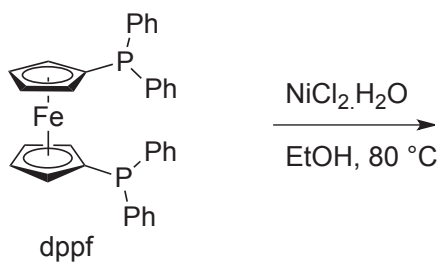

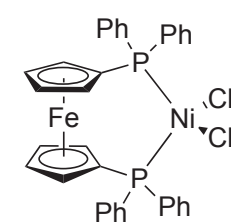

(dppf) NiCl2
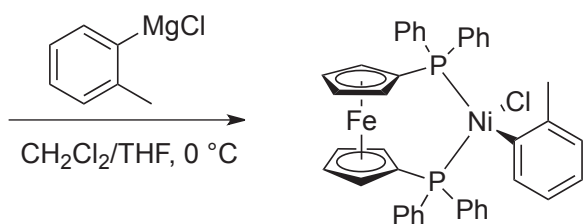

(dppf) $\mathrm{Ni}(\mathrm{o}-\mathrm{Tol}) \mathrm{Cl}$
Ni-dppf
Scheme 7. Preparation of the air stable Ni-dppf catalyst according to Jamison et al. ${ }^{[27]}$

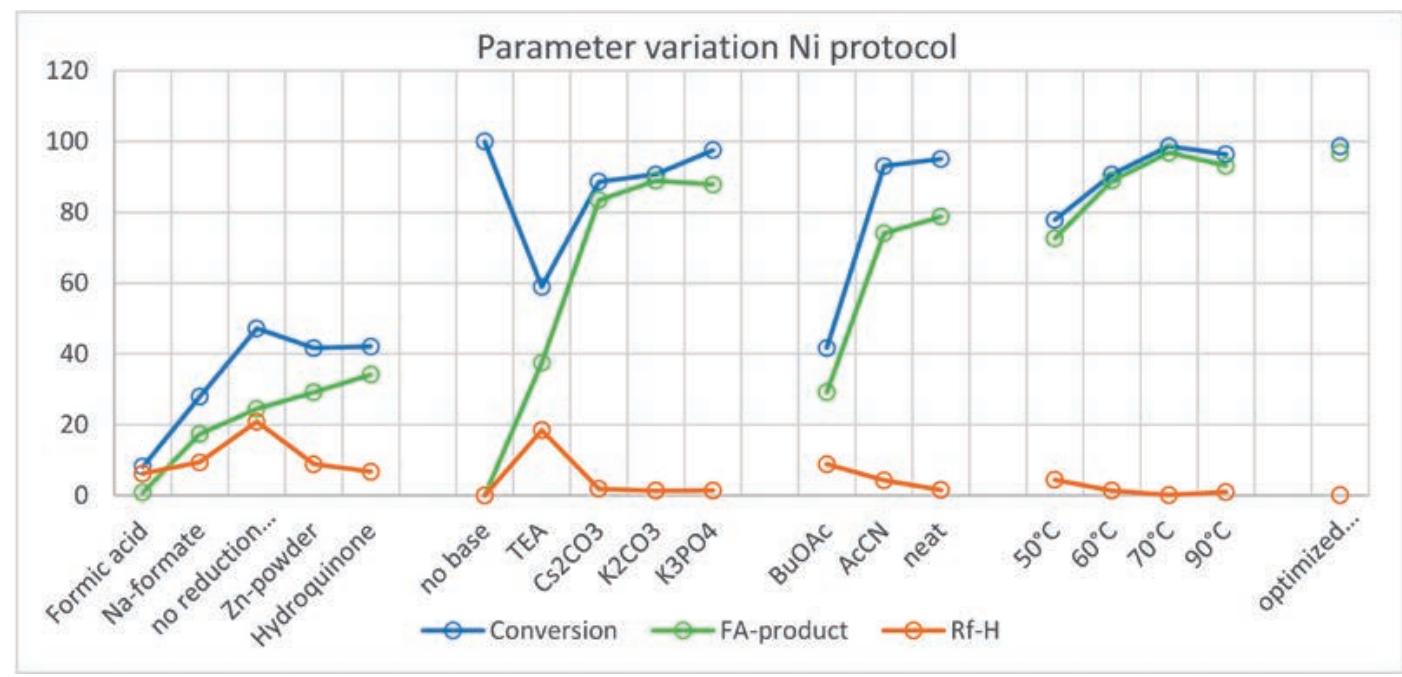

Fig. 8. Parameter variation of the Ni protocol in the reaction of aniline with perfluoropropyl bromide. 
Fig. 9. Optimization of the reaction temperature and time within an experimental design.
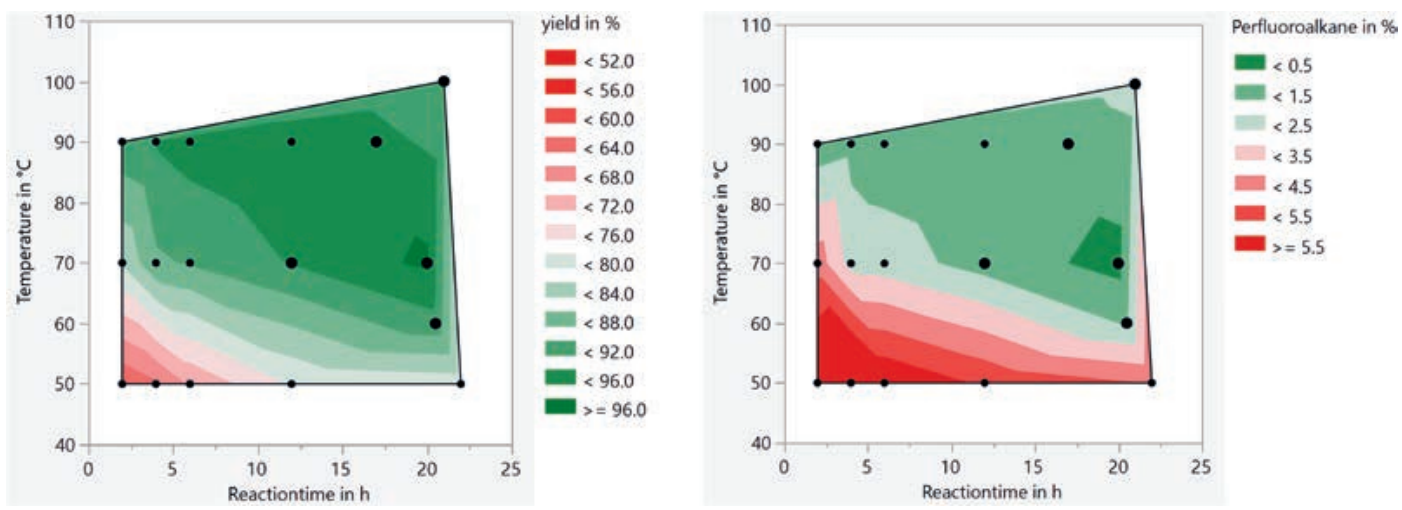

tions are rare and two principal approaches in this respect were considered and developed. Within this work the dithionite method was useful for electron-rich substrates. The four catalytic protocols in question were applicable for a broad range of substrates and showed reasonable to good yield even for electron deficient substrates. Especially interesting are the first-row metal-catalyzed systems. These provide efficient possibilities for fluoroalkylations for a broad range of substrates with cost-effective non-noble metal catalysts. We are convinced that these new systems have a great potential, opening new ways for industrially applicable fluoroalkylation processes.

\section{Acknowledgements}

A substantial amount of the work was conducted in collaboration between LIKAT (Leibniz-Institut für Katalyse e.V.) and Lonza AG (now Arxada AG) as well as student stages at Lonza AG (now Arxada AG). We are grateful to all contributors for their engagement and enthusiasm creating these new possibilities.

Received: September 3, 2021

[1] G. Siegemund, W. Schwertfeger, A. Feiring, B. Smart, F. Behr, H. Vogel, B. McKusick, P. Kirsch, in 'Ullmann's Encyclopedia of Industrial Chemistry', Wiley-VCH, Weinheim, 2016, pp. 1-56, https://doi.org/10.1002/14356007.a11_349.pub2.

[2] G. Sedelmeier, J. Sedelmeier, Chimia 2017, 71, 730, https://doi.org/10.2533/chimia.2017.730.

[3] L. M. Jarvis, Chem. Eng. News 2019, 97, https://cen.acs.org/pharmaceuticals/drug-development/new-drugs-2018/97/i3\#.

[4] L. M. Jarvis, Chem. Eng. News 2020, 98, https://cen.acs.org/pharmaceuticals/drug-development/new-drugs-2019/98/i3.

[5] a) S. Barata-Vallejo, B. Lantano, A. Postigo, Chem. Eur. J. 2014, 20 , 16806, https://doi.org/10.1002/chem.201404005; b) J.-A. Ma, D. Cahard, Chem. Rev. 2004, 104, 6119, https://doi.org/10.1021/cr030143e; c) J. Nie, H.-C. Guo, D. Cahard, J.-A. Ma, Chem. Rev. 2010, 111, 455, https://doi.org/10.1021/cr100166a; d) J. Baudoux, D. Cahard, Org. React. 2007, 69, 347, https://doi.org/10.1002/0471264180.or069.02; e) S. Barata-Vallejo, M. V. Cooke, A. Postigo, ACS Catal. 2018, 8, 7287, https://doi.org/10.1021/acscatal.8b02066; f) B. Lantano, M. R. Torviso, S. M. Bonesi, S. Barata-Vallejo, A. Postigo, Coord. Chem. Rev. 2015, 285, 76, https://doi.org/10.1016/j.ccr.2014.11.004; g) S. BarataVallejo, S. M. Bonesi, A. Postigo, Org. Biomol. Chem. 2015, 13, 11153, https://doi.org/10.1039/C5OB01486G; h) S. Barata-Vallejo, D. E. Yerien, B. Lantano, A. Postigo, Curr. Org. Chem. 2016, 20, 2838, https://doi.org/10.2174/1385272820666160614080432; i) B. Lantano, S. Barata-Vallejo, A. Postigo, Org. Biomol. Chem. 2018, 16, 6718, https://doi.org/10.1039/C8OB01653D.

[6] a) T. Umemoto, Chem. Rev. 1996, 96, 1757, https://doi.org/10.1021/cr941149u; b) S. Noritake, N. Shibata, S. Nakamura, T. Toru, M. Shiro, Eur. J. Org. Chem. 2008, 3465, https://doi.org/10.1002/ejoc.200800419; c) I. Kieltsch, P. Eisenberger, A. Togni, Angew. Chem. Int. Ed. 2007, 46, 754, https://doi.org/10.1002/anie.200603497; d) J. Charpentier, N. Früh, A. Togni, Chem. Rev. 2015, 115, 650, https://doi.org/10.1021/cr500223h.

[7] a) G. Siegemund, W. Schwertfeger, A. Feiring, B. Smart, F. Behr, H. Vogel, B. McKusick, in 'Ullmann's Encyclopedia of Industrial
Chemistry', Wiley-VCH Verlag GmbH \& Co. KGaA, 2000, https://doi.org/10.1002/14356007.a11_349; b) E. Greiner, A. Bland, T. Kumamoto, E. Zhang, 'Chemical Economics Handbook', 2020, 543.7000, https://ihsmarkit.com/products/fluorocarbons-chemical-economics-handbook.html; c) E. Greiner, A. Bland, T. Kumamoto, E. Zhang, 'Chemical Economics Handbook', 2019, https://ihsmarkit.com/products/fluoroelastomers-chemical-economics-handbook.html; d) E. Greiner, A. Bland, T. Kumamoto, E. Zhang, 'Chemical Economics Handbook', 2019, https://ihsmarkit.com/products/fluoropolymers-chemical-economics-handbook.html.

[8] a) W.-Y. Huang, J. Fluorine Chem. 1992, 58, 1, https://doi.org/10.1016/ S0022-1139(00)82787-6; b) C. Wakselman, J. Fluorine Chem. 1992, 59, 367, https://doi.org/10.1016/S0022-1139(00)80331-0; c) G. G. Furin, Russ. Chem. Rev. 2000, 69, 491, https://doi.org/10.1070/RC2000v069n06ABEH000353; d) C.-P. Zhang, Q.-Y. Chen, Y. Guo, J.-C. Xiao, Y.-C. Gu, Chem. Soc. Rev. 2012, 41, 4536, https://doi.org/10.1039/c2cs15352a; e) W.-Y Huang, F.-H. Wu, Isr. J. Chem. 1999, 39, 167, https://doi.org/10.1002/ ijch.199900022; f) L. He, K. Natte, J. Rabeah, C. Taeschler, H. Neumann, A. Brueckner, M. Beller, Angew. Chem. Int. Ed. 2015, 54, 4320, https://doi.org/10.1002/anie.201411066; g) K. Natte, R. V. Jagadeesh, L. He, J. Rabeah, J. Chen, C. Taeschler, S. Ellinger, F. Zaragoza, H. Neumann, A. Brueckner, M. Beller, Angew. Chem. Int. Ed. 2016, 55, 2782, https://doi.org/10.1002/anie.201511131; h) S. Zhang, N. Rotta-Loria, F. Weniger, J. Rabeah, H. Neumann, C. Taeschler, M. Beller, Chem. Commun. 2019, 55, 6723, https://doi.org/10.1039/C9CC01971E; i) S. Zhang, F. Weniger, F. Ye, J. Rabeah, S. Ellinger, F. Zaragoza, C. Taeschler, H. Neumann, A. Brückner, M. Beller, Chem. Commun. 2020, 56, 15157, https://doi.org/10.1039/D0CC06652D.

[9] Y.-R. Luo, 'Comprehensive Handbook of Chemical Bond Energies', CRC Press, Boca Raton, 2007, https://doi.org/10.1201/9781420007282.

[10] a) J. P. Coe, M. J. Paterson, J. Chem. Theory Comput. 2015, 11, 4189, https://doi.org/10.1021/acs.jctc.5b00543; b) C. J. Cramer, in 'Essentials of Computational Chemistry', John Wiley \& Sons, Ltd, Chichester, 2002, p. 191 to 232.

[11] H. Bing-Nan, H. Wei-Yuan, H. Chang-Ming, Acta Chim. Sin. 1981, 39, 481, http://sioc-journal.cn/Jwk_hxxb/CN/abstract/article_342352.shtml.

[12] a) C. E. Housecroft, A. G. Sharpe, in 'Inorganic Chemistry', Pearson, 2008, p; b) V. Vegunta, Master Thesis KTH Royal Institute of Technology, Stockholm, Sweden, 2016, https://kth.diva-portal.org/smash/get/ diva2:1052027/FULLTEXT01.pdf ; c) S. M. Lough, J. W. McDonald, Inorg. Chem. 1987, 26, 2024, https://doi.org/10.1021/ic00260a004; d) G. Blankenhorn, E. G. Moore, J. Am. Chem. Soc. 1980, 102, 1092, https://doi.org/10.1021/ja00523a028.

[13] a) Z.-Y. Long, Q.-Y. Chen, J. Org. Chem. 1999, 64, 4775, https://doi. org/10.1021/jo9900937; b) Z.-Y. Long, Q.-Y. Chen, Tetrahedron Lett. 1998 39, 8487, https://doi.org/10.1016/S0040-4039(98)01906-6.

[14] a) C.-P. Zhang, Q.-Y. Chen, J.-C. Xiao, Y.-C. Gu, J. Fluorine Chem. 2009, 130, 671, https://doi.org/10.1016/j.jfluchem.2009.05.005; b) H.-P. Cao, Q.-Y. Chen, J. Fluorine Chem. 2007, 128, 1187, https://doi.org/10.1016/j.jfluchem.2007.04.018; c) F.-H. Wu, B.-N. Huang, L. Lu, W.-Y. Huang, J. Fluorine Chem. 1996, 80, 91, https://doi.org/10.1016/ S0022-1139(96)03503-8; d) B. J. Grady, D. C. Dittmer, J. Fluorine Chem. 1990, 50, 151, https://doi.org/10.1016/S0022-1139(00)80493-5; e) W. Huang, L. Lu, Chin. J. Chem. 1991, 9, 174, https://doi.org/10.1002/ cjoc. 19910090212 .

[15] W. Ghattas, C. R. Hess, G. Iacazio, R. Hardré, J. P. Klinman, M. Réglier, J. Org. Chem. 2006, 71, 8618, https://doi.org/10.1021/jo061022s.

[16] J. L. Howell, B. J. Muzzi, N. L. Rider, E. M. Aly, M. K. Abouelmagd, J. Fluorine Chem. 1995, 72, 61, https://doi.org/10.1016/0022-1139(94)03176-Z.

[17] a) F. Zaragoza, D. Zollinger, WO2019030187, 2019; b) S. K. Dhingra, K. S. Shekhawat, K. Kumar, R. Anand, IN201611011512A, 2017; c) K. Kodaka, K. Okumura, JP2011153114A, 2011; d) T. Kono, H. Mita, Y. Ikushima, JP2012153635A, 2012; e) C. Mertens, W. Hallenbach, H.-G. Schwarz, 
WO2016174052A1, 2016; f) W. Hallenbach, H.-G. Schwarz, K. Ilg, U. Goergens, J. Koebberling, A. Turberg, N. Boehnke, M. Maue, R. Velten, T. Harschneck, J. J. Hahn, S. Horstmann, WO2015067647A1, 2015; g) F. Erver, F. Memmel, A. Arlt, W. Hallenbach, T. Harschneck, C. Schotes, R. Velten, WO2018104214A1, 2018; h) J. Xu, H. Wu, X. Cheng, L. Xu, H. Yang, N. Sun, H. Yu, CN109206335A, 2019; i) H. Okura, WO2013150988A1, 2013; j) C. Luo, Q. Xu, C. Huang, L. Luo, J. Zhu, R. Zhang, G. Huang, D. Yin, Org. Process Res. Dev. 2020, 24, 1024, https://doi.org/10.1021/ acs.oprd.0c00028; k) Y. Kobayashi, H. Daido, H. Katsuta, M. Nomura, H. Tsukada, A. Hirabayashi, Y. Takahashi, Y. Aoki, A. Kawahara, Y. Fukazawa, M. Hirose, US20110201687A1, 2011.

[18] a) C. Taeschler, M. Beller, H. Neumann, L. He, K. Natte, S. Ellinger, F. Zaragoza Doerwald, WO2015185677A1, 2015; b) C. Taeschler, F. Zaragoza Doerwald, S. Ellinger, M. Beller, H. Neumann, L. He, K. Natte, WO2016071425A1, 2016.

[19] C. Amatore, E. Carre, A. Jutand, M. A. M'Barki, G. Meyer, Organometallics 1995, 14, 5605, https://doi.org/10.1021/om00012a029.

[20] TURBOMOLE V7.4.1 2019, a development of University of Karlsruhe and Forschungszentrum Karlsruhe GmbH, 1989-2007, TURBOMOLE GmbH, since 2007, available from http://www.turbomole.com.

[21] A. G. Sergeev, A. Zapf, A. Spannenberg, M. Beller, Organometallics 2008, 27, 297, https://doi.org/10.1021/om700889b.

[22] C. Taeschler, M. Beller, H. Neumann, L. He, K. Natte, S. Ellinger, F. Zaragoza Doerwald, WO2015185677A1, 2015.

[23] S. Zhang, F. Weniger, C. R. Kreyenschulte, H. Lund, S. Bartling, H Neumann, S. Ellinger, C. Taeschler, M. Beller, Catal. Sci. Technol. 2020, 10, 1731, https://doi.org/10.1039/c9cy02460c.

[24] a) C. Taeschler, F. Zaragoza Doerwald, S. Ellinger, M. Beller, H. Neumann, F. Weniger, WO2019020726A1, 2019; b) C. Taeschler, T. Belser, S. Ellinger, F. Z. Doerwald, M. Beller, H. Neumann, F. Fischer, S. Zhang, WO2020169770A1, 2020; c) C. Taeschler, S. Ellinger, F. Z. Doerwald, M. Beller, H. Neumann, F. Fischer, S. Zhang, N. Rotta-Loria, WO2020169768A1, 2020.
[25] F. A. Westerhaus, R. V. Jagadeesh, G. Wienhöfer, M.-M. Pohl, J. Radnik, A.-E. Surkus, J. Rabeah, K. Junge, H. Junge, M. Nielsen, A. Brückner, M. Beller, Nat. Chem. 2013, 5, 537, https://doi.org/10.1038/nchem.1645.

[26] a) R. V. Jagadeesh, H. Junge, M.-M. Pohl, J. Radnik, A. Brückner, M. Beller, J. Am. Chem. Soc. 2013, 135, 10776, https://doi.org/10.1021/ja403615c; b) D. Banerjee, R. V. Jagadeesh, K. Junge, M.-M. Pohl, J. Radnik, A. Brückner, M. Beller, Angew. Chem. Int. Ed. 2014, 53, 4359, https://doi.org/10.1002/ anie.201310420; c) F. Chen, A.-E. Surkus, L. He, M.-M. Pohl, J. Radnik, C. Topf, K. Junge, M. Beller, J. Am. Chem. Soc. 2015, 137, 11718, https://doi org/10.1021/jacs.5b06496; d) F. Chen, C. Topf, J. Radnik, C. Kreyenschulte, H. Lund, M. Schneider, A.-E. Surkus, L. He, K. Junge, M. Beller, J. Am. Chem. Soc. 2016, 138, 8781, https://doi.org/10.1021/jacs.6b03439; e) D. Formenti, C. Topf, K. Junge, F. Ragaini, M. Beller, Catal. Sci. Technol. 2016 , 6, 4473, https://doi.org/10.1039/C5CY01925G.

[27] E. A. Standley, S. J. Smith, P. Müller, T. F. Jamison, Organometallics 2014 33, 2012, https://doi.org/10.1021/om500156q.

[28] a) Broflanilide, https://en.wikipedia.org/wiki/Broflanilide; b) B. Stephanie Reiß, World's first registration for BASF insecticide Broflanilide in Australia, https://www.basf.com/global/en/media/news-releases/2020/01/p-20-107. html.

\section{License and Terms}

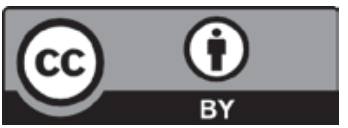

This is an Open Access article under the terms of the Creative Commons Attribution License CC BY 4.0. The material may not be used for commercial purposes.

The license is subject to the CHIMIA terms and conditions: (http:// chimia.ch/component/sppagebuilder/?view=page \&id=12).

The definitive version of this article is the electronic one that can be found at https://doi.org/10.2533/chimia.2021.923 